Running Head: PRUDENCE AND RACIAL HUMOR

\title{
Prudence and Racial Humor: Troubling Epithets
}

\author{
Author: \\ Jonathan P. Rossing \\ Published in Critical Studies in Media Communication
}

This is the author's manuscript of the article published in final edited form as:

Rossing, Jonathan P. (2014). Prudence and Racial Humor: Troubling Epithets. Critical Studies in Media Communication, 31(4): 299 - 313. DOI: 10.1080/15295036.2013.864046 


\title{
Prudence and Racial Humor: Troubling Epithets
}

\begin{abstract}
$\underline{\text { Abstract }}$
Prudence is an essential virtue in a contemporary racial culture marked by the contingencies and the paradoxical in/stability of race and racism. Recurring controversies surrounding racial epithets exemplify this clash between deeply entrenched racial meanings on one hand and shifting conventions on the other. I argue in this essay that racial humor presents a valuable site for understanding and practicing prudential reasoning and performance. Analyzing three episodes from popular texts-The Boondocks, The Daily Show with Jon Stewart, and South Park-I illustrate the way racial humor resists prescriptive reasoning and creates possibilities for audiences to practice prudence.
\end{abstract}

Keywords: Race/Racism; Humor; Prudence; Boondocks; South Park; The Daily Show 


\section{Prudence and Racial Humor: Troubling Epithets}

Racial culture demands prudence: practical knowledge necessary to make wise judgments and act responsibly in contingent circumstances. One word epitomizes the necessity of prudential reasoning in relation to race—nigger. ${ }^{1}$ Laden with a sordid history of oppression, this epithet consistently elicits visceral reactions and fuels anxieties about racism, and yet the epithet openly circulates in vernacular discourse and popular culture. The slur exemplifies the paradox of race: it dramatizes both the material consequences and the instability of racial constructions (Flores \& Moon, 2002). Because of this paradoxical tension the slur frequently unsettles conventions of race. In these moments, normative discussions about racial judgments and performances permeate public discourse via talk radio, (entertainment) news, opinion columns, magazines, (video) blogs, chat rooms, classrooms, and more. These moments merit attention because they provide opportunities for practicing knowledge-in-action amidst contingency. Said otherwise, these discourses inform our capacity for prudence within a fraught landscape on which the fictions and realities of race collide.

Consistent with classical rhetorical education, people learn prudence through consideration of practical wisdom as it is embodied in complex cases, individual texts, and situational performances such as those involving this troublesome slur (Hariman, 2003; Jasinski, 1990). Unfortunately, imprudence saturates contemporary racial culture. Racial silences, protection of white privilege, and postracial, neoliberal ideologies consistently enable the avoidance of race (e.g. Enck-Wanzer, 2011; Mukherjee, 2006; Squires et al, 2010). When racial controversies break this silence public discourse frequently reinforces rigid binaries and essentialisms, rather than probing the complex cultural formations that enable certain practices 
(Hartigan, 2010). Moreover, unreflexive application of rules often governs racial judgments, particularly when the racial epithet in question surfaces. When prescriptive rules trump practical judgment, the sophisticated reasoning that cultivates prudence is diminished (Garsten, 2006, p. 10). In sum, the language of prudence is not easily divined from common habits and performances surrounding race. Where, then, might people learn flexible judgment that characterizes prudence within the context of racial culture?

Racial humor proves valuable for understanding and practicing prudence in a culture of complex, rapidly changing conventions of race. In relation to the epithet in question, Asim argued that artists, broadly considered, have the capacity to pull back "the carapace of polite society to show a larger and more revealing view of a culture in which words such as 'nigger' can be successfully spawned and popularized" (2007, p. 172). Furthermore, Nelson suggested that in contrast to abstract theorizing about prudence, removed from actual situations, stories in popular culture present "readily comprehensible, truly memorable" case studies that provide opportunities for audiences to consider practical wisdom from new vantage points as it is enacted across familiar settings (2003, p. 243). Following these insights, I argue that racial humor represents a popular forum in which the public engages conversations on race and constructs understandings of prudence. Some scholars critique racial humor as a conservative force that resists change, reinforces oppressive cultural norms, constitutes narrow identities, reifies dominant power relations, and cultivates ideologies such as postracialism (e.g., Chidester, 2008; Cooks \& Orbe, 1993; Gray, 1995; Thornton, 2011). I offer an alternative perspective in the critical debate over the possibilities and consequences of racial humor by recognizing it as a participant in struggles over prudential reasoning. From Bert Williams' vaudevillian blackface performances to contemporary sketch comedy, from folklore to stand-up, racial humor addresses 
particular problems of race and participates in shaping racial meanings and experiences (Boskin, 1997; Haggins, 2007; Watkins, 1994). By "racial humor" I refer inclusively to genres of parody, satire, stand-up, sketch comedy, and more that address particular topics, characteristics, and nuances of race. I employ the term "humor" to designate rhetorical moves and tones that cross genres and to avoid confusion with "comedy" as a specific form or structure. While each genre possesses unique characteristics, they share the feature of participating in the shaping of values, ideologies, and practices of contemporary racial culture.

In this essay, I argue for racial humor as a site for prudential education through an analysis of three exemplars: an episode of Aaron McGruder's The Boondocks, an investigative report from The Daily Show with Jon Stewart, and an episode of Trey Parker and Matt Stone's South Park. Recognized for their topical engagement with serious public affairs, these programs garner scholarly attention for the cultural work they perform (e.g. Cornwell \& Orbe, 2002; Goodnow, 2011; Weinstock, 2008). I selected the texts considered in this essay because each one constituted a direct response to a particular public controversy. Each text contributed to a public conversation regarding the conventions for judgment and performance in racial culture. These texts also feature variety in author and audience. McGruder, who is black, arguably reaches a predominantly black audience through The Boondocks. The Daily Show features a diverse team of writers and the program reaches a broader demographic audience than The Boondocks or South Park. Parker and Stone, the creators of South Park, are white and the primary audience for their show is young white men.

The argument proceeds as follows. First, I define prudence and establish its vitality for contemporary racial culture. Second, I direct attention to the particular examples of racial humor that contribute to an understanding of prudence. These exemplars illustrate how racial humor 
models flexible principles and performances characteristic of prudential action and how racial humor both participates in and provokes ongoing struggles over racial conventions. My intent throughout the analysis is neither to assert a dominant interpretation of a particular text, nor to predict specific audience reception or effects. Rather, I identify characteristics in the texts that invite a particular reading oriented toward prudence in racial culture. After discussing each text independently, I consider the collective work these texts perform as popular stories about prudential reasoning.

\section{Prudence and Race}

Prudence is a virtue characterized by both wise decision-making and performance in unpredictable socio-political circumstances. Prudence equips people "to function in a world in which 'truth' is contingent, unstable, and mired in temporal circumstance” (Terrill, 2001, p. 34). Understanding prudence begins with Aristotle's discussion of phronesis or practical wisdom (Beiner, 1983). Prudence avoids fixed standards for distinguishing good from bad, right from wrong: "excellent choice cannot be captured in universal rules, because it is a matter of fitting one's choice to the complex requirements of a concrete situation, taking all of its contextual features into account" (Nussbaum, 1986, p. 303). In lieu of strict prescriptions, practical wisdom relies on community-based principles that constitute starting points for action. These precepts provide "pointers as to what to look for in a particular situation" without binding practical wisdom or restricting one's ability to revise judgments (p. 306). The prudent actor possesses a sophisticated capacity to calibrate language, stories, political judgments, and shared principles based on contextual variables (Nelson, 2003). Prudence, then, is essential in a milieu where dynamic social conventions govern our racial interactions. We cannot understand race 
independent of previous constructions, yet each moment shapes our ability to make sense of race in the next. Therefore, wise racial judgments and performances appear differently across contexts: in public and private, in policy decisions or informal interactions at a bar or workplace. The word nigger exemplifies the necessity for flexible application of general principles to particular situations. The wide array of meanings for nigger provokes pain, turmoil, and bitter tears, but not for everyone, and not equally. Despite the word's history, it has been reclaimed, recuperated, and used in ways that solidify bonds of friendship and prompt joyful laughter. Speaking to the need for prudence, Kennedy (2003) asserts, "To be ignorant of [these] meanings and effects is to make oneself vulnerable to all manner of perils, including the loss of a job, a reputation, a friend, even one's life" (p. 4). Or in a comic register, comedian Larry Wilmore offered, "White guy plus black slang equals comedy. ... White guy plus black slang minus common sense equals tragedy" (Kennedy, 2007). In short, prudential reasoning is essential for successful navigation of such contingency.

In addition to situational reasoning, prudence requires sophisticated performance. The prudent actor carefully manages appearances; prudence, then, "is the art of making the right gesture in a public space with whatever are the available means for political action" (Hariman, 1991, p. 28). Prudence as performance is understood through analogy to improvisation. A jazz virtuoso must understand scales and arpeggios before creatively composing melodies. An improvisational comedian must develop a repertoire of commonplace jokes before inventing comic scenes. Likewise, prudent performances demand sensitivity to cultural conventions while modifying those conventions to suit contextual complexities (Nelson, 2003; Terrill, 2001). Imagine listening to a popular song that includes a racial epithet. The slur is objectionable in most contexts, but when singing along do you utter the word? More important, will you adapt 
your performance in the privacy of your home, in your car, or at a club with friends? Emily Bernard (2005) raises similar questions for a classroom setting, where texts such as The Adventures of Huckleberry Finn or Kennedy's Nigger: The Strange Career of a Troublesome Word call for students and teachers to wrestle with this slur. Is an educational setting a safe space in which to articulate the word? How might performances change depending on the racial identities of students and educators? In such scenarios, wise reasoning demands careful attention and adaptation to cultural conventions and context, and still, any judgment will remain open to contestation.

Finally, prudence is the product of struggle. Wilson (1998) argued that prudence represents a "contested sensibility that obtains meaning only through discursive practice and negotiation" (p. 131). Debates over policy or incommensurable values shape the meaning of prudence, for example. Thus, to understand prudence is to attend to competing perspectives and interests influencing common conventions. In other words, " $[\mathrm{N}] \mathrm{o}$ practice can be adequately articulate and self-critical until it compares its own moves and maxims with those of other practices" (Nelson, 2003, p. 231). In relation to the word nigger, prudence is always in the process of construction and contestation. Principles such as freedom of speech, human rights, or anti-racism animate debates over the slur's usage. On one hand, the slur has been effectively stigmatized. Its usage is rare in mainstream discourse with the exception of select circles. "Eradicationists" argue that the word is so loathsome that it should be removed completely from our vernacular (Kennedy, 2003). On the other, artists and entertainers of all racial identities utter it with varying aims and effects (Asim, 2007; Kennedy, 2003). Such contests epitomize Wilson's (1998) claim that there can be no "settled and widely accepted notion of what is prudent" 
because the terms of prudence emerge in "a contested space that political actors struggle to control through discourse" (p. 133).

Race is mutable. Unruly racial meaning creates conditions of inescapable uncertainty. Thus, it is imperative to identify sources that participate in the struggle over prudential reasoning by modeling guidelines for discerning judgment and performance. As I illustrate in the following case studies, racial humor is well-suited to serve as an inventional resource for prudential guidelines by generating new frameworks that both expose imprudence and render intelligible previously unconsidered actions.

\section{Racial Humor: Case Studies for Prudential Education}

The Boondocks: Resisting Mechanization

Racial epithets often elicit mechanical reactions that lack careful scrutiny of contextual variables. Frequently, when racial remarks disrupt expected conventions, the ensuing conversation about race concentrates on whether the incident was "racist" or not (Hartigan, 2010). Automatized concerns over racism fail to consider a broader range of possibilities that might complicate racial judgments. For example, a teacher drew scrutiny for prompting an educational conversation over the use of the slur in The Adventures of Huckleberry Finn (Fox, 2007). In perhaps the most jarring evidence of imprudent mechanization, a teacher in North Carolina received mandatory sensitivity training for introducing the homonymic vocabulary word "niggardly" (Jones, 2002). These disquieting demonstrations of unsophisticated judgments suggest that commonplace judgments about the salience of race lack complexity and nuance. Instead, prudential reasoning in contemporary racial culture should follow a neo-racial sensibility 
that recognizes racism as a real problem with serious consequences, but resists explaining every racial transgression as an instance of racism and white supremacy (Banks, 2009).

An episode of The Boondocks titled "The S Word" troubled these bureaucratized reactions by satirizing a 2007 incident in Louisville, Kentucky, in which a high school teacher called a student "nigger" (McGruder \& Barnes, 2008). The teacher argued that his students used the word regularly and he was simply employing their jargon. The targeted student wanted the teacher fired; instead, the teacher was suspended for ten days without pay. The Boondocks marked its association with this incident by mimicking almost scene-for-scene the news report on the incident from WHAS11 in Louisville. Riley Freeman, an 11-year-old gangsta rapper wannabe, has been called a "nigga" by his teacher. The teacher alleged that Riley used the word incessantly, but Riley claimed he was made to feel like "less of a person" and claimed, "All he saw when he looked at me was a black nigger." The episode's storyline showcased the prescriptive narratives that direct the conversation toward narrow disputes over the extent to which white racism or black pathologies explain the disruption (Hartigan, 2010). For example, Reverend Rollo Goodlove, a caricature of Al Sharpton or Jesse Jackson, thrust himself into the controversy in order to seek justice for this racist affront by way of a law suit against the school district. Pundits sparred over whether Riley is the victim of the white teacher's racism or whether the teacher is the hero for standing up to a "foulmouthed gang member." The teacher framed himself as an unfortunate victim of a double standard given the pervasive presence of the slur in popular music. In sum, the episode portrayed the tendency to identify categorically victims and racists and to position such incidents within limited frameworks of (reverse) racism or white supremacy, rather than to examine nuanced variables that betray shifting racial conventions. 
Humor often relies on exposing the incongruities and ideological contradictions that accompany rigid prescriptions (Bergson, 1911). Indeed, The Boondocks highlighted the contradictions and limitations inherent in such automatized responses to racial matters, thereby inviting consideration of contingency and complexity. For example, the episode problematized the essentializing frame of "racist" with a comic portrayal of the teacher as a fool who cannot quite fathom the ramifications of his actions. The teacher's runny mouth leaks not hateful vitriol but uncorked ignorance as he muddles through justifications for his transgression: "[Riley] calls me nigga. He calls the other kids nigga. He calls himself nigga all the time. Nigga this. Nigga that. Nigga, please. ...He says it so much, I don't even notice it anymore.” And just as in the real-life incident, the teacher resorts to visual aids to explain his confusion over the rules that govern the epithet — one sheet of paper with "nigga" and "nigger" and another paper with "2 completely different words." Such comic framing casts the teacher as a fool who botches racial interactions rather than a racist. The characterization troubles a frame that irrevocably positions the teacher as a villain. Importantly, however, the comic frame neither relieves the teacher of accountability for his actions nor diminishes the harm and pain of hearing the word.

Comic incongruities also problematize the notion that the slur necessarily participates in racist discourse. When Robert Freeman claimed the teacher caused Riley to suffer "a tremendous, unspecified mental and physical damage," Huey, Riley's brother, noted “you both say the word nigger all the time"-so much, in fact, that Riley "thought it was his name until he was three." When Riley discovers that his teacher will only receive a ten day suspension he declared, "That's a damn shame! You can call a nigger a 'nigger' and keep your job.” Such scenes exemplify a technique for exposing incongruities: a character enacting the very actions she condemns (Bergson, 1911). These violations problematize prescriptive judgments that treat 
nigger as if its meaning were static and necessarily racist by exposing the inevitable contradictions that render such judgments untenable. The humor encourages rejection of mechanization in favor of greater attention to contingency.

The Boondocks, then, provides a case study on evaluating contextual complexities of racial matters. Wise decision making must not be bound either by fixed standards that unequivocally identify racists or racism or by post-racial narratives that deny the salience of race. Prudence in contemporary racial culture requires a "neo-racial" sensibility that resists both "the reflexive tendency to simplistically depict contemporary controversies as yet further evidence of racism" as well as the post-racial fantasy (Banks, 2009, p. 43). Thus, the prudential response to contemporary racial controversies such as those that surround the epithet nigger would recognize the salience of race and the pervasive racial inequalities entrenched by history while simultaneously accounting for the shifts in racial meaning and practice in contemporary society.

\section{The Daily Show with Jon Stewart: Finding Balance}

The struggle over harmful speech often oscillates between two extremes: censorship or absolute freedom of speech. On one hand, public culture attempts to remedy racial animus with moratoriums and bans. The Laugh Factory instituted a fine for any performer who used "hateful words” (Risling, 2006). In 2007, Los Angeles and New York City Councils passed resolutions announcing a "voluntary ban" on the word. The NAACP staged a burial of the epithet complete with a coffin and gravesite. On the other hand, people argue that First Amendment rights protect any utterance of the slur. Such was the case when radio personality Laura Schlessinger used the epithet 11 times on her program. Media watch dog groups demanded her termination, but Schlessinger preemptively resigned in protest of this perceived violation of her freedom of 
speech. Neither banning words nor arguing for unrestrained freedom achieves the dynamic balance that characterizes prudence. In both cases a universal principle trumps the particulars in a case. Prudential action requires the ability to balance competing, often incommensurable positions in complex political situations such as coordinating individual interests with the public good (Hariman, 2003; Terrill, 2001).

When New York City Council proposed a ban on the epithet, The Daily Show with Jon Stewart dramatized this struggle between censorship and freedom of speech. Host Jon Stewart foregrounded the tension as he introduced the report: "A word of warning. Some people in our audience may find the language in our next segment to be offensive." He shrugged as if to suggest little concern over their offense, enacting a dismissiveness that privileged the right to speak freely. In contraposition to this performance, however, he immediately raised the question of censorship: "But if a word is offensive does that mean that it should never be heard?" (Stewart \& Albanese, 2007). The mock-investigative report featured correspondents Larry Wilmore and John Oliver interviewing the ban's sponsor Councilman Leroy Comrie and citizens on the streets of New York City. Oliver, who is white, dutifully avoided the slur and discussed the ban with stammering ineptitude. Conversely, Wilmore, who is black, used the slur without restraint. During the interview with Councilman Comrie, for example, Oliver consistently deferred to Wilmore who eagerly uttered the word. Oliver inquired, "You want to ban this word—um, Larry?" He pointed to Wilmore for assistance: "Nigger." Oliver continued, "Thank you. What he said. Ah. Is the word, um —" Again Wilmore assisted: "Nigger." "—offensive to everyone, or just to ..." Oliver paused and gestured toward Comrie as if to ask if Comrie alone is troubled by the word or if only certain people are offended. Wilmore, however, finished Oliver's statement: "Niggers." Oliver objected strongly, "No! ... don’t use that term, please!” Oliver asked black 
residents of Harlem what they think about "The Ban." Unable to utter the epithet, he resorts to vague generalities and a game of charades before he is reduced to staring silently at an interviewee. Wilmore, on the other hand, glibly used the slur in his interactions with white residents of Manhattan's upper west side. His questions begin directly: "The City Council wants to ban the word nigger. Do you think that's a good idea?" However, they quickly become more flagrant: "So you're against niggers not for niggers?" "You either want to keep niggers or get rid of niggers, which one is it?"

Humor characteristically flouts conventions. This mock-investigative report exaggerated the tendency toward either inept silence or unrestrained speech. On one hand, Oliver's performance problematizes strict censorship. An unwavering interdiction stunted his ability to discuss the issue productively. His awkward reticence to utter the slur caused indirectness and confusion. On the other hand, Wilmore's brazen use of the epithet troubled the ideal of absolute freedom. He flagrantly uttered nigger in any context for any audience, at one point even proudly demonstrating the word's versatility across parts of speech. His lack of regard or restraint caused discomfort and withdrawal. Both Oliver's guarded self-censorship and Wilmore's raffish tongue stymied productive conversation. Portraying side-by-side the folly of these incommensurable positions, The Daily Show animated the need for balanced, situational reasoning and created space for revised thought and action. Prudential wisdom cannot be mandated by formulaic bans or unbridled speech. Instead, prudence seeks balance between the competing tendencies to purge public culture of the slur and to defend an unchecked freedom to utter such words. Troubling the imprudence of the ban and the potential harms of unrestrained speech, this report invites a search for a middle ground of critical judgment that accepts the use of objectionable language in particular instances while challenging it others. 


\section{South Park: Prudential Practice}

In order to learn contingent reasoning and sophisticated balance people must be allowed space to err and opportunities to adapt. Simply, prudence requires practice. Through ongoing practice people discover and refine "how [prudential principles] will work, when they will prove apt, and where they won't' (Nelson, 2003, p. 237). Unfortunately, mechanized reactions to racial controversies surrounding nigger often curtail opportunities for practicing prudence because the threat of shaming and castigation cause people to withdraw from such interactions. In November 2006, comedian Michael Richards' epithet-laden performance at the Los Angeles Laugh Factory provoked national outrage. When a pair of black audience members heckled Richards during his performance, he repeatedly called them "niggers" and taunted, "Fifty years ago we'd have you upside down with a fucking fork up your ass." The exchange spread via YouTube and the public swiftly admonished Richards as a racist. As further evidence of bureaucratized judgment in response to racial epithets, public outcry focused predominantly on how many times he used the slur with only scant attention to the arguably more insidious invocation of lynching and physical violence. To be sure, Richards' heinous verbal assault deserved correction; however, this incident exemplifies the tendency for any misstep, actual or perceived, to result in tarnished reputations, lost jobs, and social castigation, even when the alleged offender is innocent of any intention to insult or harm (Kennedy, 2003). Ritual vilification contributes to the impression that racial silence is safer than risking social defilement. Consequently, a culture of trepidation restricts the practice and development of wise reasoning and performances.

South Park’s “With Apologies to Jesse Jackson” (Parker, Stone, \& Garefino, 2007) troubled such ritualistic vilification and contrasted these tendencies with a storyline that modeled 
earnest, committed trial and error intended to strengthen an interracial friendship. Airing three months after the Richards incident, the episode satirized the conventional castigation that follows controversies involving a racial epithet. Randy Marsh appeared in the bonus round of Wheel of Fortune. The puzzle category: "People Who Annoy You." Confronted with the puzzle “N_GGERS” Randy stammered, “I know it, but I don't think I should say it.” With sudden resolve, Randy announced, "I'd like to solve the puzzle — niggers!" A buzzer interrupted tense silence. The missing letter illuminated: NAGGERS. Following this public transgression, the community shuns Randy, strangers condemn and taunt him, and a gang of vigilantes threatens his life. Randy meets with Jesse Jackson to atone for his mistake, but the public disciplining continues. Even Randy's son, Stan, suffers consequences as a rabblerousing student broadcasts a "race war" between Stan and his friend Token Black, the lone black student in the school. Randy finds solace among similarly targeted "nigger-guys” including Michael Richards and Mark Fuhrman, the detective whose use of the epithet became a crucial factor in the O. J. Simpson trial. Randy resisted his inclusion in this group of offenders, but Richards called attention to the ritual vilification underway: "All they see is just another damn nigger-guy." This storyline dramatizes the tendency toward sharp punishments in response to racial transgressions which foreclose opportunities for practicing prudence. Without practice, people will not learn to attend to contingency nor develop the capacity for wise judgments and adaptive performance. Consequently, automatized punishments continue to thwart prudential practice and perpetuate a cycle of imprudent judgments.

A second storyline offered an alternative to this cycle of punishment and, instead, modeled the reflexive practice of prudence. Stan Marsh, Randy's son, attempted repeatedly to make amends with his friend Token. First, he excused his father's actions as "no big deal;" then, 
he dismissed Token's feelings telling him to forget about the incident. Token retorted, "It may be a mistake, but you don't know how it feels when that word comes up." After his father apologized to Jesse Jackson, Stan claimed that "everything is cool.” In response, Token asserted the unique fabric of his feelings: "Jesse Jackson is not the emperor of black people!" After a school assembly where a little person spoke about the power of language, Stan explained that he knew how Token must feel, but his effort once again met rebuke: "So black people are midgets?" In their penultimate encounter, Stan demanded a solution: "I've done everything I can to make this right. You have no reason to still be mad." Token reiterated, "I have every reason to be mad. You just don't get it!" "What the hell do you want from me?!" Stan begged. "Nothing!" "Then stop being mad!" "No!" Finally, Stan achieved the most prudent performance: "I get it now-I don't get it! I've been trying to say that I understand how you feel, but I'll never understand. I'll never really get how it feels for a black person to have somebody use the ' $\mathrm{N}$ word."' Content, Token concluded, "Now you get it, Stan. ... Thanks, dude."

This series of interactions powerfully illustrates how contingent reasoning and adaptive performance emerge through prudential practice. If the best way to develop prudence is to learn how to "cultivate active relationships with those people with whom one is most often rhetorical" and "to create situations in which [actors] have to be rhetorical" (Darwin, 2003, p. 24), then Stan and Token model such a sustained, adaptive relationship from which prudence is cultivated. Token resisted punishing Stan for his missteps, yet notably Token does not dampen his anger or frustration. His performance suggests that outrage and indignation do not necessarily lead to castigation. With each error, Stan calibrated his performance to account for broader perspectives. He began with self-centered reasoning that tended only to his own perspective and then attempted to apply overly broad rules by presuming that Jesse Jackson's pardon or a little 
person's experience with taunts were equivalent to Token's forgiveness or reactions. Stan demanded a solution, but Token refused to mandate a mechanical remedy. Repeatedly, he forced Stan to practice contextual judgment and adaptive performance. Importantly, Stan had the space to err and to adapt to his mistakes, which ultimately resulted in a satisfying, trustworthy performance. He discovered a middle ground where no prescription will suffice and where every judgment remains open to revision. Indeed, prudence in contemporary racial culture must acknowledge that "getting it" is always temporary; the moment one "gets it" is the moment to submit that judgment for critique once again. An alternative to dominant conventions of racial discourse, this story provides guidelines for adaptive performances and "acts of confident, flexible, but forgivable judgment" (Nelson, 2003, pp. 250-52). It models the prudential characteristic of determining a responsible course of action based on often incommensurable racial perspectives, competing material realities of race, and unpredictable responses.

\section{Participants in struggles over prudence}

Collectively these texts should be understood not only as case studies in prudential reasoning, but also as participants in ongoing contests over prudence. First, these texts highlight multiple voices that vie to shape the contours of prudence. Multiplicity is often the source of incongruities that drive racial humor; thus, these examples of racial humor invite attention to people whose divergent perspectives complicate wise reasoning in moments of racial judgment. The Boondocks showcases competing perspectives, in part, through a series of short interview segments in which multiple parties share their perspectives on the history, place, and fate of the epithet. The Daily Show features this polyvocality through the interactions among the reporters Oliver and Wilmore, the sponsor of the proposal to ban the epithet, and everyday people from the 
streets of New York City. Perhaps South Park most adeptly foregrounds the contested nature of prudence through a mise-en-scène that strategically toggles back and forth between subject positions in order to create powerful juxtapositions. For example, the focus shifted purposefully between Randy and an incredulous, all-black audience as he explained that they could not imagine how it feels to have a label (nigger-guy) evoke the negative emotions of a painful history. Later, as Randy argued for a law banning the slur nigger-guy before a predominantly white panel of United States Senators, the camera toggled to the lone black senator who opposed the measure. As white people celebrated the success of this ban the focus shifted to a group of black bystanders watching in silent disbelief. Throughout all the texts, these shifts in attention provide opportunities to encounter multiplicity and to wrestle with the complex relationships for which prudence must account.

Racial humor poses a challenge for those who do not wish to reproduce problematic meanings and history, but these artists model perspicacious judgment through their inventive processes. Said otherwise, these responses provide opportunities to learn from the ways each artist enacted prudence through the creation of the text. In particular, these artists demonstrate contextual reasoning through doubled-meanings. The use of epithets in racial humor requires sensitivity to recognize that "the meanings of most words or phrases depend on the speaker's intonation and the context in which a remark occurs" (Watkins, 1994, pp. 131-132). Each artist exposed the epithet's historical context and the outrage and pain it elicits, yet doubled meanings also allowed each artist to deploy nigger ambiguously and use it against itself. Throughout The Boondocks, for example, McGruder dots the storyline with a wide variety of meanings for the epithet. It appears as a term of endearment, a racist attack, a self-reference, a general reference for other black people by another black character, and more. Wilmore's street interviews on The 
Daily Show construct ambiguity over nigger as a reference to the epithet or as a general descriptor for black people. Wilmore asked white people if they wanted to "keep niggers or get rid of them." When one interviewee rejected the ban, Wilmore pushed, "So you're a niggerlover?" In the only text created exclusively by white artists, South Park creators Parker and Stone strategically deployed the slur in context of an ambiguous new slur, "nigger-guy." This variant was deployed when strangers taunted Randy, a convenience store denied him service, and a gang chased and cornered him at gunpoint. Randy spoke of the "painful history" this word evoked. On one hand, these scenes become intelligible when the original epithet replaces niggerguy, a substitution that variously recalls Jim Crow segregation, lynch mobs, and systemic oppression. On the other hand, nigger-guy served as a substitute for racist. Randy earned the label when he patronizingly told a black audience that they couldn't imagine how a single word might evoke a painful history and the lone black Senator named a colleague "the biggest niggerguy in Washington.” In each instance, carefully crafted ambiguity complicates narrow characterizations of the epithet as either universally harmful or innocently impotent and invites the audience to attend carefully to the contextual variables that influence racial knowledge. The artists illuminate its relationship to racial oppression as they simultaneously foreground the inescapable ambiguity and fragmentation of racial meaning. Multiplying meaning across contexts, these artists struggle against the sentries of popular culture who would vigilantly patrol unfavorable words. Instead, they encourage subtler analysis of meaning while attending to the reality that race continues to matter powerfully.

\section{Racial humor and prudential education}


Racial epithets and the public controversies that surround them illustrate the necessity for prudential reasoning, performance, and practice in contemporary culture. Racial humor provides a critical forum in which to locate a language of prudence. The Boondocks, The Daily Show with Jon Stewart, and South Park join many other comedians, sit-coms, comic strips, and more to model wise reasoning and performance vis-à-vis racial epithets and to struggle over prudence. To be sure, simple exposure to racial humor will not be sufficient to provoke reflection on or development prudence. Thus, I do not argue that racial humor necessarily inspires progressive action or dismantles racial oppression. To issue such a universal edict for racial humor would be as imprudent as unilateral rejection of its potential to participate in prudential education. Instead, I have upheld the dynamic characteristics of racial humor that make it an important participant in struggles over prudential reasoning. These humorous responses to specific controversies provide compelling alternatives to the fervent debates that epithets spark. Together, these texts illuminate the often unexamined complexities, contradictions, and conventions that shape our experiences of race and our understanding of racism. They problematize bureaucratized judgments such as explaining racial matters through the lens of either racism or post-racialism and, instead, encourage flexible responses to contingent circumstances. Thus, these texts exemplify the potential for racial humor to participate in ongoing struggles over racial judgments and performances.

Of course, humor will always be open to varied audience interpretations. Audiences struggle over the possible meanings of racial humor and activate meanings differently depending on their experiences (Fiske, 1986; Means Coleman, 2002; Perks, 2010). The Boondocks narrative could be read as a critique of media sensationalism surrounding race, as evidence of double standards and hypocrisy among African Americans, or as a way to pathologize African 
Americans and assign them blame for the slur's continued use. Oliver and Wilmore's Daily Show report on the New York City Council ban might be understood as a critique of censorship or they might be viewed as smart alecs who gleefully rib Councilman Comrie by finding inventive ways to repeat the word he wishes to ban. Likewise, Randy Marsh in South Park might be understood as an unreflexive character whose stubborn insistence on his narrow experience prevents prudential action. Conversely, it would be possible to view Randy as a heroic victim waging battle against the perils of political correctness. I contend that this polysemy strengthens racial humor as an important site for understanding prudence. Racial humor provokes vital conversations about appropriate conventions and judgments that further shape understandings of prudence across different contexts (Rossing, 2011). As particular audiences make sense of popular stories from their respective frames of reference, they join in (re)defining the guidelines that inform prudence in racial culture.

Because racial humor often resists automatized judgments, attends to the ways racial meaning and racism have shifted, and features competing views about how best to respond to racial matters, it arguably provides a safer space for prudential practice and struggle than other discursive sites featuring more prescriptive responses. Prudence cannot emerge in a setting that quells contests over sophisticated judgment and performance; rather, people must learn to manage the contingency through trial and error. Illuminating the ways racial humor models prudence and provokes conversations about racial judgment equips critical scholar-educators to use these texts in order to guide dialogues and explorations that might shape richer understandings of prudence. These popular lessons may prove valuable to our critical teaching practices if we encourage students to accept racial humor's invitation to wrestle with the complexities and contingencies of racial judgment and performance. Recognizing racial humor 
Prudence and Racial Humor 23

as a partner to critical scholarship and education, we must mobilize its pedagogic potential even as we remain attentive to its problems and limitations. 


\section{NOTES}

[1] I recognize the power this epithet wields and the varied emotional reactions at hearing the slur or seeing it in print. As a white scholar, my critical engagement with this word and my decision to use it in context may provoke dissent. I welcome critical reactions as I believe, in line with my argument, prudential judgment emerges in contested practice. Throughout the essay, I use nigger and "n word" as they are used in the texts I analyze. In my discussion I use the epithet sparingly and as necessary for clarity. I avoid euphemisms ("the n word") or typographical variants (n-----) on the grounds that symbolic placeholders neither seriously engage nor adequately challenge the complexities of such trigger words. 


\section{BIBLIOGRAPHY}

Asim, J. (2007). The $n$ word: Who can say it, who shouldn't, and why. New York, NY: Houghton Mifflin Company.

Banks, R. R. (2009). Beyond colorblindness: Neo-racialism and the future of race and law scholarship. Harvard BlackLetter Law Journal, 25, 41-56.

Beiner, R. (1983). Political judgment. Chicago, IL: University of Chicago Press.

Bergson, H. (1911). Laughter: An essay on the meaning of the comic. Trans. Cloudesten Brereton and Fred Rothwell. New York: Macmillan.

Bernard, E. (2005). Teaching the N-Word. The American Scholar. Retrieved from http://theamericanscholar.org/teaching-the-n-word/

Boskin, J. (Ed.). (1997). The humor prism in twentieth century America. Detroit, MI: Wayne State University Press.

Chidester, P. (2008). May the circle stay unbroken: Friends, the presence of absence and the rhetorical reinforcement of whiteness. Critical Studies in Media Communication, 25, 157-174. doi: 10.1080/15295030802031772

Cornwell, N. C. and Orbe, M. P. (2002). Keepin' it real and/or “sellin' out to the man": AfricanAmerican responses to Aaron McGruder's The Boondocks. In R. R. Means Coleman (ed.), Say it Loud! African-American audiences, media, and identity (pp. 27-43). New York, NY: Routledge.

Darwin, T. J. (2003). Pathos, Pedagogy, and the Familiar. In J. Petraglia and D. Bahri (Ed.) The Realms of Rhetoric: The Prospects for Rhetoric Education (pp. 23-38). Albany, NY: State University of New York Press.

Douglas, M. (1975). Implicit meanings: Essays in anthropology. New York, NY: Routledge. 
Prudence and Racial Humor 26

Enck-Wanzer, D. (2011). Barack Obama, the Tea Party, and the Threat of Race: On Racial Neoliberalism and Born Again Racism. Communication, Culture \& Critique 4, 23-30. doi:10.1111/j.1753-9137.2010.01090.x

Fiske, J. (1986). Television: Polysemy and popularity. Critical Studies in Mass Communication, 3, 391-408. doi:10.1080/15295038609366672

Flores, L. A., \& Moon, D. G. (2002). Rethinking race, revealing dilemmas: Imagining a new racial subject in Race Traitor. Western Journal of Communication, 66, 181-207.

Fox, L. (2007, November 1). Huckleberry Finn n-word lesson draws controversy. Dallas Morning News.

Garsten, B. (2006). Saving persuasion. Cambridge, MA: Harvard University Press.

Goodnow, T. (Ed.) (2011). The Daily Show and rhetoric. Lanham, MD: Lexington Books.

Gray, H. (1995). Watching race: Television and the struggle for ' blackness. Minneapolis, MN: University of Minnesota Press.

Haggins, B. (2007). Laughing mad: The black comic persona in post-soul America. New Brunswick, NJ: Rutgers University Press.

Hariman, R. (1991). Prudence/performance. Rhetoric Society Quarterly, 21, 26-35. doi:10.1080/02773949109390914

Hariman, R. (Ed.). (2003). Prudence: Classical virtue, postmodern practice. University Park, PA: The Pennsylvania State University Press.

Hartigan, Jr., J. (2010). What can you say? America's National conversation on race. Stanford, CA: Stanford University Press.

Jasinski, J. (1990). The status of theory and method in rhetorical criticism. Western Journal of Communication, 65, 249-270. doi:10.1080/10570310109374705 
Jones, S. (2002, September 4). Teacher reprimanded for word choice. Morning Star (Wilmington, NC).

Kennedy, R. (2003). Nigger: The Strange Career of a Troublesome Word. New York, NY: Vintage Books.

Kennedy, R. (2007, April 15). That's (not) funny. New York Times. Retrieved from http://www.nytimes.com

McGruder, A., \& Barnes, R. (Executive Producers). (2008, January 21). The S-word. [Television series episode]. The Boondocks. New York, NY: Sony Pictures Television.

Means Coleman, R. R. (Ed.). (2002). Say it loud! African-American audiences, media, and identity. New York, NY: Routledge.

Mukherjee, R. (2006). The racial order of things: Cultural imaginaries of the post-soul era. Minneapolis, MN: University of Minnesota Press.

Nelson, J. S. (2003). Prudence as republican politics. In R. Hariman (Ed.), Prudence: Classical virtue, postmodern practice (pp. 229-258) University Park, PA: The Pennsylvania State University Press.

Nussbaum, M. C. (1986). The fragility of goodness: Luck and ethics in Greek tragedy and philosophy. New York, NY: Cambridge University Press.

Parker, T., Stone, M., \& Garefino, A. (Executive Producers). (2007, March 7). With apologies to Jesse Jackson [Television series episode]. South Park. New York, NY: Parker-Stone Studios.

Perks, L. G. (2010). Polysemic scaffolding: Explicating discursive clashes in Chappelle's Show. Communication, Culture, \& Critique, 3, 270-289. doi:10.1111/j.1753-9137.2010.01070.x 
Risling, G. (2006, November 28). Black leaders seek end to use of racial slur in entertainment. Associated Press. [retrieved from Lexis Nexis].

Rossing, J. (2011). Comic provocations in racial culture: Barack Obama and the "Politics of Fear.” Communication Studies, 62, 422-438. doi:10.1080/10510974.2011.588077

Squires, C., Watts, E. K., Vavrus, M. D., Ono, K. A., Feyh, K., Calafell, B. M. \& Brouwer, D. C. (2010). What is this "post-" in postracial, postfeminist ... (Fill in the blank)? Journal of Communication Inquiry, 34, 210-253. doi:10.1177/0196859910371375

Stewart, J. \& Albanese, R. (Executive producers). (2007, March 28). The n word [Television series segment]. The Daily Show with Jon Stewart. New York, NY: Comedy Central.

Terrill, R. E. (2001). Protest, prophecy, and prudence in the rhetoric of Malcolm X. Rhetoric \& Public Affairs, 4, 25-53. doi:10.1353/rap.2001.0016

Thornton, D. J. (2011). Psych's comedic tale of Black-White friendship and the lighthearted affect of 'post-race' America. Critical Studies in Media Communication, 28, 424-449. doi:10.1080/15295036.2010.518621

Watkins, M. (1994). On the real side: A history of African American comedy from slavery to Chris Rock. New York, NY: Lawrence Hill Books.

Weinstock, J. A. (Ed.). (2008). Taking South Park seriously. Albany, NY: State University of New York Press.

Wilson, K. (1998). The contested space of prudence in the 1874-1875 civil rights debate. Quarterly Journal of Speech, 84, 131-149. doi:10.1080/00335639809384210 